\title{
KHẢO SÁT ĐA DẠNG DI TRUYỀn VÀ XÁC LẬP CHỈ THỊ PHÂN TỬ CHO VIỆC NHẬN DẠNG MỘT SỐ DÒNG BƠ (Persea americana Miller) ĐÃ QUA SƠ Bộ TUYỀN CHỌN TẠI LÂM ĐỒNG
}

\author{
Lê Ngọc Triệu ${ }^{a^{*}}$, Nguyễn Hoàng Phong ${ }^{\mathrm{a}}$, Mai Tiến Đạt ${ }^{\mathrm{a}}$, \\ Thái Thạch Bích ${ }^{\mathrm{a}}$, Nguyễn Thanh Tiền ${ }^{\mathrm{a}}$, Lê Đình Vĩnh Bảo ${ }^{\mathrm{a}}$, \\ Nguyễn Khắc Quang ${ }^{\mathrm{a}}$, Phan Ngọc Quỳnh Như ${ }^{\mathrm{a}}$ \\ ${ }^{a}$ Khoa Sinh học, Trường Đại học Đà Lạt, Lâm Đồng, Việt Nam \\ Lịch sử bài báo \\ Nhận ngày 12 tháng 07 năm 2016 | Chỉnh sửa ngày 30 tháng 08 năm 2016 \\ Chấp nhận đăng ngày 10 tháng 09 năm 2016
}

\begin{abstract}
Tóm tắt
Việc khảo sát, đánh giá về kiểu hình cũng nhu kiểu gen là cần thiết nhằm làm tăng hiệu quả cho quá trình nhận dạng, phát triển và chọn tạo giống mói đối với cây trồng. Nguồn gen thuộc một số dòng bo đã qua chọn lọc để canh tác được thu thập tù một số nơ trong địa bàn tỉnh Lâm Đồng để phân tích đa dạng di truyền và nhận dạng giống. Đặc điểm so bộ về hình thái quả và năng suất của 11 dòng bo tiềm năng đã được ghi nhận để hố trợ cho co sở dũ liệu nhận dạng dòng. Với đặc trung nhận dạng DNA thu nhận được với 10 mồi ISSR, chúng tôi thu được tổng số 125 band điện di trên gel để tiến hành phân tích đa dạng di truyền tập hợp 11 mẫu khảo sát đại diện cho 11 dòng trên, kết quả cho thấy: tập hợp mẫu có mức dị hơp trông đơi (chỉ số đa dạng gene) đạt $H_{e}=h=0,3072$, chi số Shannon đạt: I $=0,4608$, tỷ lẹ band đa hìn: $P P B=91,84 \%$. Cüng sủ dụng 10 mồi ISSR nhu trên, tù đặc trung nhận dạng DNA của 18 mẫu đại diện cho 6 dòng bo tiềm năng (mối dòng 3 mẫu), dựa trên sự xuất hiện hay thiếu vắng các band đặc trung đã xác lập được 9 chỉ thị phân tư đơn và 25 chỉ thị phân tử kép để nhận dạng 06 dòng bo này. Những kết quả buớc đầu thu được cung cấp nhũng dĩ liệu cần thiết phục vu cho công tác chọn tạo, phát triển giống bo nói chung và xác định chủng loại giống với 6 dòng bo tiềm năng.
\end{abstract}

Từ khóa: Chỉ số Shannon; Chỉ thị phân tử; ISSR; Mức độ dị hợp trông đợi.

\section{MỞ ĐẦU}

Bơ (Persea americana Miller) là một loại cây có nguồn gốc từ Mexico và Trung Mỹ, là một loài thực vật có hoa, hai lá mầm, họ Lauraceae. Bơ là loại trái cây rất giàu dưỡng và có giá trị, ngoài ăn tươi quả bơ còn được chế biến thành các món rất hợp khẩu vị như sa lát, sinh tố, súp, nước sốt và sử dụng làm mỹ phẩm.

Theo thống kê của FAO, cây bơ được trồng tại 63 nước với tổng diện tích 417 ngàn ha, sản lượng 3.078 ngàn tấn mỗi năm, năng suất trung bình 7,4 tấn/ha,

\footnotetext{
*Tác giả liên hệ: Email: trieuln@ dlu.edu.vn
} 
hàng năm lượng xuất khẩu 491,5 ngàn tấn và giá trị xuất khẩu 606,6 triệu USD (Gazit \& Degani, 2002; John, Greg, Brandon, \& Gary, 2012; Pliego-Alfaro \& Murashige, 1988).

Ở Châu Á, cây bơ được trồng khá rộng rãi ở các nước Đông Nam Á như Indonesia, Philippine, Thái Lan, Việt Nam và Trung Quốc. Indonesia là quốc gia đứng thứ 4 trên thế giới và đứng đầu các nước Đông Nam Á về sản xuất bơ. Các giống bơ được trồng ở Việt Nam hiện nay có nguồn gốc nhập nội từ lâu thuộc các chủng giống Chủng Mexican, Guatemalan và West Indian. Qua quá trình canh tác, lai tạp không chủ ý và lai tạo có chủ đích đã hình thành nên nhiều dòng bơ được canh tác và thương mại hiện nay. Lâm Đồng là nơi có tiềm năng cho việc trồng bơ và hiện đã có nhiều dòng/ giống được trồng gồm: các giống nhập nội Hass, Reed, Booth7; các dòng/giống được được Trung tâm Nghiên cứu và Phát triển cây trồng thành phố Bảo Lộc chọn lọc (còn được gọi là các dòng bo "có số") như dòng 33 , dòng 34 , dòng 36 , dòng 04 , dòng $05 .$. ; Các dòng bơ được đưa về từ các tỉnh bạn lân cận: HO, TO, BM00, BM02...; và các dòng bơ được người dân tự chọn lọc như Hải Triều 1, Hải Triều 2, dòng 34 lai (trồng từ hạt của dòng 34)....

Trước khi việc xác định trình tự trở nên phổ biến, việc nghiên cứu về phân loại thực vật và nhận dạng các chủng giống nông nghiệp không định hướng vào vùng mang tính bảo tồn dựa vào các kỹ thuật hình thành DNA fingerprint là rất phổ biến ở nhiều đối tượng. Hiện nay, cách làm này vẫn được duy trì và phát triển để tiến hành xác định, xác thực các chủng giống.

Sự đa dạng di truyền giúp cho một loài sinh vật cụ thể có khả năng đáp ứng lại những điều kiện khác nhau của môi trường sống, từ đó có khả năng tồn tại khi có sự biến đổi của môi trường cũng như có thể mở rộng khu phân bố ra các khu vực. Đánh giá sự đa dạng di truyền của một tập hợp mẫu là một trong những việc làm cần thiết để có thể phác thảo ra những chiến lược bảo tồn và phát triển giống cây trồng.

Ưu thế của các kỹ thuật phân tử là có khả năng nhanh chóng (1) xác định được sự đa dạng di truyền trong các tập đoàn giống cây trồng thông qua tập hợp các đặc trưng nhận dạng DNA (DNA fingerprint) và (2) phân biệt các chủng giống quan tâm mà không bị tác động gây sai lệch bởi các yếu tố ngoại cảnh như trong trường hợp dựa hoàn 
toàn trên hình thái. Có nhiều loại marker phân tử khác nhau nhằm làm nảy sinh DNA fingerprint, tuy nhiên với các ưu điểm chính là không cần có dữ liệu trình tự dùng cho việc xây dựng mồi, tiến trình phân tích bao gồm việc sử dụng PCR, chỉ một lượng ít khuôn mẫu DNA được yêu cầu (khoảng 5-50ng cho một phản ứng), hơn thế, ISSR phân bố ngẫu nhiên trên toàn bộ bộ gene (Zietkiewicz, Rafalski, \& Labuda, 1994; Li, Li, Yang, Cheng, \& Zhang, 2011), chỉ thị ISSR được sử dụng trong nghiên cứu này để đánh giá đa dạng tập đoàn bơ qua tuyển chọn tại Lâm Đồng và xác lập marker nhận dạng cho các dòng.

Công tác xác định các chủng giống cây trồng và đánh giá đa dạng di truyền các tập đoàn giống cây trồng đã được tiến hành tại Việt Nam, tuy nhiên, công tác này chưa được triển khai trên các dòng/giống bơ tại Việt Nam.

\section{VẬT LIỆU VÀ PHƯƠNG PHÁP NGHIÊN CƯUU}

\subsection{Vật liệu}

Đối tượng nghiên cứu là 11 dòng bơ và các đặc điểm cơ bản về năng suất và hình thái quả đã được chọn lọc ở một số địa bàn thuộc tỉnh Lâm Đồng gồm các dòng 04, 05, Hải triều 1, Hải Triều 2, 34, 36, 34 lai, HO, TO, BM00, BM02.

\subsection{Phương pháp nghiên cứu}

Khảo sát canh tác các dòng/giống bơ: Triển khai khảo sát thực địa các vùng trồng bơ tại Lâm đồng, ghi nhận các chủng giống chủ lực và các chủng giống tiềm năng. Tham khảo các nghiên cứu có trước và thu thập các thông tin về đặc điểm quả, năng suất và các đặc tính nông học khác đối với từng giống.

\subsection{Phương pháp tách chiết, kiểm tra nồng độ, chất lượng DNA}

Mẫu lá của các dòng bơ khảo sát được tách chiết $\mathrm{ADN}$ theo quy trình $\mathrm{CTAB} 1$ có cải tiến bằng cách $\mathrm{SDS} 10 \%$ vào đệm chiết, kiểm tra số lượng và chất lượng $\mathrm{DNA}$ dựa vào tương quan mật độ quang đo ở hai bước sóng $260 \mathrm{~nm}$ và $280 \mathrm{~nm}$ (Weising, Nybom,Wolff, \& Kahl, 2005). 


\subsection{Sử dụng kỹ thuật ISSR để hình thành các đặc trưng nhận diện DNA (DNA fingerprinting)}

Khuếch đại DNA: Phản ứng PCR được thực hiện với dung tích $20 \mu \mathrm{l}$ chứa 2 $\mathrm{mM} \mathrm{MgCl} 2,0.25 \mathrm{mM}$ mỗi loại dNTP, 1U Taq DNA polymerase (ThermoScientific), 0.2 $\mu \mathrm{M}$ mồi và khoảng 30 ng khuôn mẫu DNA, BSA $0.5 \%$. Quá trình khuếch đại DNA được tiến hành trên máy luân nhiệt Biometra 48 giếng với chương trình nhiệt sau: $94{ }^{\circ} \mathrm{C}$ trong 5 phút; 10 chu kỳ, mỗi chu kỳ có tiến trình nhiệt $94{ }^{\circ} \mathrm{C}$ trong 45 giây, Nhiệt độ bắt mồi thích hợp $+5\left(\mathrm{~T}_{\mathrm{a}}+5\right){ }^{0} \mathrm{C}\left(\mathrm{T}_{\mathrm{a}}\right.$ trong khoảng tùy mồi $50-57^{0} \mathrm{C}$, xem thêm ở Bảng 4.3.) trong 45 giây, giảm dần $0,5{ }^{\circ} \mathrm{C} /$ chu kỳ, kéo dài mạch ở $72^{\circ} \mathrm{C}$ trong 1 phút 30 giây; 36 chu kỳ, mỗi chu kỳ có tiến trình nhiệt $94{ }^{\circ} \mathrm{C}$ trong 45 giây, Nhiệt độ bắt mồi thích hợp $\left(\mathrm{T}_{\mathrm{a}}\right)$ trong 45 giây, kéo dài mạch ở $72^{\circ} \mathrm{C}$ trong 1 phút 30 giây; Bước kéo dài mạch cuối cùng ở $72^{\circ} \mathrm{C}$ trong 15 phút.

Trong nghiên cứu này chúng tôi đã sử dụng 20 mồi ISSR được cung cấp bởi NAPS Unit (UBC primers set \#9) để thử nghiệm trên mỗi mẫu đại diện cho 1 dòng khảo sát, có 10 mồi cho đa hình với tính ổn định cao được chọn để sử dụng tạo DNA fingerprint trên 3 mẫu/dòng bơ khảo sát được trình bày ở Bảng 1 .

Bảng 1. Đặc điểm các mồi ISSR sử dụng trong nghiên cứu

\begin{tabular}{|c|c|c|c|c|c|c|c|}
\hline \multirow[b]{2}{*}{ STT } & \multirow[b]{2}{*}{ Tên mồi } & \multirow[b]{2}{*}{ Trình tự } & \multicolumn{3}{|c|}{$\begin{array}{l}\text { Đa dạng di truyền } \\
11 \text { dòng bơ }\end{array}$} & \multicolumn{2}{|c|}{$\begin{array}{c}\text { Chỉ thị phân tử } \\
\text { nhận dạng } 6 \text { dòng } \\
\text { bơ }\end{array}$} \\
\hline & & & $\begin{array}{c}\mathrm{T}_{\mathrm{a}} \\
\left({ }^{0} \mathrm{C}\right)\end{array}$ & $\begin{array}{l}\text { Số band } \\
\text { ghi nhận }\end{array}$ & $\begin{array}{r}\mathrm{PPB} \\
(\%)\end{array}$ & $\begin{array}{l}\text { Số band } \\
\text { ghi nhận }\end{array}$ & $\begin{array}{r}\text { PPB } \\
(\%)\end{array}$ \\
\hline 1 & ISSR 808 & $5^{\prime}-(\mathrm{AG})_{8} \mathrm{C}-3^{\prime}$ & 52 & 7 & 71,4 & 17 & 100,0 \\
\hline 2 & ISSR 844B & $5^{\prime}-(\mathrm{CT})_{8} \mathrm{GC}-3^{\prime}$ & 52 & 10 & 90,0 & 18 & 94,4 \\
\hline 3 & ISSR 17899B & $5^{\prime}-(\mathrm{CA})_{6} \mathrm{GG}-3^{\prime}$ & 54 & 16 & 100,0 & 12 & 100,0 \\
\hline 4 & HB9 & $5^{\prime}-(\mathrm{GT})_{6}$ GG-3' & 52 & 7 & 85,7 & 14 & 85,7 \\
\hline 5 & HB14 & $5^{\prime}-(\mathrm{CTC})_{3} \mathrm{GC}-3^{\prime}$ & 52 & 10 & 100,0 & 11 & 90,9 \\
\hline 6 & HB13 & $5^{\prime}-(\mathrm{GAG})_{3}$ GC-3' & 52 & 11 & 90,9 & 10 & 72,7 \\
\hline 7 & UBC 856C & $5^{\prime}-(\mathrm{AC})_{8} \mathrm{CA}-3^{\prime}$ & 52 & 9 & 88,9 & 14 & 85,7 \\
\hline 8 & UBC $856 \mathrm{~T}$ & $5^{\prime}-(\mathrm{AC})_{8}$ TA-3' & 52 & 11 & 81,9 & 13 & 76,9 \\
\hline 9 & UBC 873 & $5^{\prime}-(\mathrm{GACA})_{4}-3^{\prime}$ & 52 & 15 & 100,0 & 14 & 92,9 \\
\hline \multirow[t]{2}{*}{10} & UBC 859G & $5^{\prime}-(\mathrm{TG})_{8}$ GC-3' & 51,5 & 2 & 100,0 & 02 & 100,0 \\
\hline & Tổng thể & & & 98 & 91,8 & 125 & \\
\hline
\end{tabular}


Sản phẩm khuếch đại được phân tách trên gel agarose $2 \%$, sử dụng đệm TBE với điện thế 60 Volt trong 3 giờ, gel sau điện di được nhuộm với ethidium bromide $(0,5$ $\mu \mathrm{g} / \mathrm{ml}$ ), và được chụp ảnh dưới các ánh sáng cực tím có bước sóng 254/312 nm bằng hệ thống Micro Doc Gel Documentation (Cleaver Scientific, Mỹ), từ đó có được DNA fingerprint theo từng mồi ở dạng ảnh gel điện di.

\subsection{Phân tích đa dạng di truyền dựa trên các đặc trưng nhận dạng DNA (DNA fingerprinting)}

Bởi chỉ thị ISSR mang tính trội, mỗi dãy band DNA trên gel sau điện di được xem là đại diện cho một locus gồm hai allele (Williams, Kubelik, Livak, Rafalski, \& Tingey, 1990). Các band ISSR được ghi nhận về sự hiện diện (với ký hiệu là 1) hay vắng mặt (với ký hiệu là 0 ) để lập ma trận dữ liệu nhị phân theo từng mồi sử dụng. Tổng hợp các ma trận nhị phân theo mồi để xây dựng ma trận nhị phân tổng thể.

Phần mềm Microsoft Office Excel 2007 được sử dụng để tính toán các thông số về đa dạng di truyền. Các thông số này bao gồm:

- Tỷ lệ phần trăm band đa hình: Công thức tính: $P P B=\mathrm{n}_{\mathrm{pj}} / \mathrm{n}_{\text {total }} \times 100$ với $P P B$ là tỷ lệ phần trăm band đa hình, $\mathrm{n}_{\mathrm{pj}}$ là số lượng band đa hình và ntotal là tổng số band ghi nhận.

- Mức độ dị hợp trông đợi trung bình: Công thức tính: $\quad H_{\mathrm{e}}=\Sigma_{\mathrm{j}}^{\mathrm{L}} \mathrm{h}_{\mathrm{j}} / \mathrm{L} ; \mathrm{h}_{\mathrm{j}}=1-$ $\Sigma \mathrm{p}_{\mathrm{i}}^{2}$

Với $h_{j}$ là mức độ dị hợp tử của locus thứ $\mathrm{j}$, $\mathrm{p}_{\mathrm{i}}$ là tần số của allele thứ $\mathrm{i}$ ở locus thứ $\mathrm{j}, H_{e}$ là mức độ dị hợp trông đợi trung bình cho tất cả các locus khảo sát và L là tổng số locus. (de Vicente, Lope, \& Fulton, 2003).

Ngoài ra, phần mềm Popgen32 được sử dụng để đánh giá đa dạng di truyền tập hợp các dòng bơ khảo sát, hai chỉ số đa dạng là chỉ số đa dạng gene (h) và chỉ số đa dạng Shannon (I).

Hệ số tương đồng và sơ đồ dạng cây về quan hệ phát sinh giữa các mẫu khảo sát được tính toán bằng phần mềm NTSys 2.1 (Rohlf, 2004). 


\subsection{Xây dựng chỉ thị phân tử cho việc nhận dạng các dòng bo}

Hai kiểu chỉ thị phân tử sau được xây dựng thông qua kết quả thực nghiệm:

- Kết quả phân tích ảnh điện di và ma trận dữ liệu về sự xuất hiện/thiếu vắng các băng hình thành từ các mồi cho thấy có sự xuất hiện/thiếu vắng một cách đặc biệt của băng chỉ có ở ba mẫu thuộc một dòng duy nhất và băng chỉ thiếu vắng ở ba mẫu thuộc cùng một dòng duy nhất (Chỉ thị đơn - chỉ sử dụng 1 mồi).

- Trong trường hợp không xác định được, tiến hành xác định chỉ thị phân từ theo band xuất hiện hay vắng mặt chỉ ở tất cả các mẫu thuộc hai dòng, sau đó tìm sự khác biệt giữa hai dòng theo phương thức a (Chỉ thị kép - sử dụng từ 2 mồi trở lên).

\section{KẾT QUẢ VÀ BÀN LUẬN}

\section{1. Đặc điểm sơ bộ về hình thái và năng suất các dòng bo khảo sát}

Qua điều tra khảo sát, đề tài đã thu thập được 11 dòng bơ có chất lượng tốt và được thị trường ưa chuộng. Kết quả thể hiện ở Bảng 2.

\section{Bảng 2. Đặc điểm sơ bộ về hình thái và năng suất các dòng bơ khảo sát}

\begin{tabular}{|c|c|c|c|}
\hline Stt & Dòng & Nơi thu thập & Đặc điểm cơ bản về hình thái và năng suất \\
\hline 1 & 04 & Bảo Lâm & $\begin{array}{l}\text { Năng suất: } 300 \mathrm{~kg} / \text { cây/năm } \\
\text { Quả thon dài, thịt quả vàng nhạt, ráo, dẻo } \\
\text { Khi chín vỏ màu xanh } \\
\text { Cõ̃ hạt: Trung bình }\end{array}$ \\
\hline 2 & 05 & Di Linh & $\begin{array}{l}\text { Năng suất: } 220 \mathrm{~kg} / \mathrm{cây} / \mathrm{năm} \\
\text { Thịt qủa vàng, hạt nhỏ } \\
\text { Quả thuôn dài } \\
\text { Vỏ chín màu xanh } \\
\text { Cỡ hạt: Trung bình }\end{array}$ \\
\hline 3 & $\begin{array}{l}\text { Hải } \\
\text { Triều } 2\end{array}$ & Bảo Lộc & $\begin{array}{l}\text { Năng suất: Vẫn chưa rõ } \\
\text { Màu quả khi chín : Xanh } \\
\text { Hình hạng quả: Ovan hơi dọc } \\
\text { Thịt quả: Vàng nhạt, không sơ, đặc đều } \\
\text { Hạt: Tròn, không lắc }\end{array}$ \\
\hline
\end{tabular}


Bảng 2. Đặc điểm sơ bộ về hình thái và năng suất các dòng bơ khảo sát (tiếp theo)

\begin{tabular}{|c|c|c|c|}
\hline $\mathrm{Stt}$ & Dòng & Nơi thu thập & Đặc điểm cơ bản về hình thái và năng suất \\
\hline 4 & $\begin{array}{l}\text { Hải } \\
\text { Triều } 1\end{array}$ & Bảo Lộc & $\begin{array}{l}\text { Năng suất: } 650 \mathrm{~kg} / \text { cây/năm } \\
\text { Màu quả khi chín : Xanh } \\
\text { Hình hạng quả: Ovan dài đều } \\
\text { Thịt quả: Tương tự giống bơ Pháp } \\
\text { Hạt: Dính thịt, không lắc, hình tròn }\end{array}$ \\
\hline 5 & 34 & Bảo Lộc & $\begin{array}{l}\text { Năng suất: } 300 \mathrm{~kg} / \mathrm{cây} / \text { năm } \\
\text { Chín vỏ da màu xanh thuôn dài, cơm vàng, hạt bé (có quả không } \\
\text { hạt ) } \\
\text { Chiều dài quả từ } 25 \mathrm{~cm} \text { đến } 35 \mathrm{~cm}\end{array}$ \\
\hline 6 & 36 & Đức Trọng & $\begin{array}{l}\text { Năng suất: } 200-300 \mathrm{~kg} / \mathrm{cây} / \text { năm } \\
\text { Vỏ chín có màu xanh, hình bầu dục, thịt quả dày màu vàng đậm, } \\
\text { dẻo, béo } \\
\text { Trọng lượng quả trung bình } 750 \mathrm{~g} \\
\text { Kích cỡ hạt: Trung bình }\end{array}$ \\
\hline 7 & 34 lai & Bảo Lộc & $\begin{array}{l}\text { Năng suất: } 250 \mathrm{~kg} / \mathrm{cây} / \text { năm } \\
\text { Chín vỏ da màu xanh hơi tròn } \\
\text { Hạt trung bình, không dính vỏ }\end{array}$ \\
\hline 8 & $\mathrm{HO}$ & Đức Trọng & $\begin{array}{l}\text { Năng suất: } 160 \text { - } 180 \mathrm{~kg} / \mathrm{cây} / \text { năm } \\
\text { Trọng lượng quả: } 380 \text { - } 450 \mathrm{~g} \\
\text { Vỏ quả già màu tím nhạt, thịt quả vàng kem, khá béo, không xơ. } \\
\text { Hạt gắn khít thịt quả nhưng dễ tách. } \\
\text { Hoa sai, khả năng đậu quả cao }\end{array}$ \\
\hline 9 & TO & Đức Trọng & $\begin{array}{l}\text { Năng suất: } 150 \text { - } 200 \mathrm{~kg} / \mathrm{cây} / \mathrm{năm} \\
\text { Trọng lượng quả: } 380 \text { - } 450 \mathrm{~g} \\
\text { Vỏ quả già màu tím nhạt, hơi sần, không xơ } \\
\text { Kích cỡ hạt: Trung bình } \\
\text { Hoa trổ đồng thời và đều nhau trên toàn cây }\end{array}$ \\
\hline 10 & BM00 & Đức Trọng & $\begin{array}{l}\text { Năng suất: } 160 \text { - } 180 \mathrm{~kg} / \mathrm{cây} / \mathrm{năm} \\
\text { Trọng lượng quả: } 380 \text { - } 450 \mathrm{~g} \\
\text { Vỏ quả già màu tím, mỏng, nhẵn bóng, cơm dày, ít sơ } \\
\text { Kích cỡ hạt: Trung bình }\end{array}$ \\
\hline 11 & BM02 & Đức Trọng & $\begin{array}{l}\text { Năng suất: } 140 \text { - } 180 \mathrm{~kg} / \mathrm{cây} / \mathrm{năm} \\
\text { Trọng lượng quả: } 180 \text { - } 200 \mathrm{~g} \\
\text { Quả hình tròn đều } \\
\text { Vỏ quả chín xanh, hơi sần, } \\
\text { Kích cỡ hạt: Trung bình }\end{array}$ \\
\hline
\end{tabular}

\subsection{Nhận dạng các dòng bơ bằng chỉ thị phân tử}

Sử dụng 10 mồi ISSR, chúng tôi thu nhận được đặc trưng nhận dạng của 18 mẫu khảo sát với 125 band, số band thu nhận được theo từng mồi xem ở Bảng 1. 

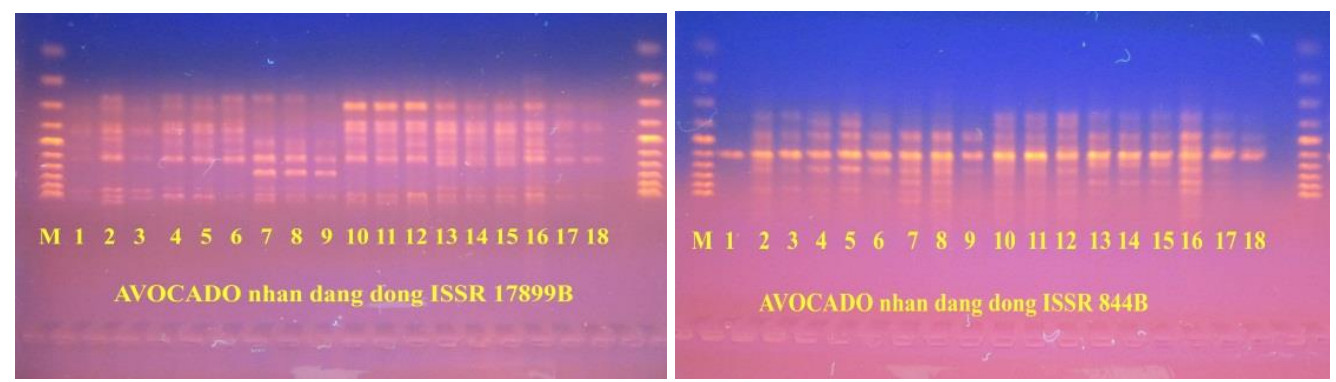

Hình 1. Ảnh gel đặc trưng nhận dạng DNA sử dụng 2 mồi 17899B và 844B với tập họ̣p 18 mẫu khảo sát để nhận dạng 06 dòng bo

Ghi chú: 1, 2, 3: các mẫu dòng 04; 4, 5, 6: các mẫu dòng $05 ; 7,8$, 9: các mẫu dòng Hải Triều 2; 10, 11 , 12: các mẫu dòng Hải Triều 1; 13, 14, 15: các mẫu dòng 34; 16, 17, 18: các mẫu dòng 36 .

Phân tích sự xuất hiện hay vắng mặt các band đặc trưng chung cho 3 mẫu khảo sát thuộc cùng dòng trong mối tương quan với các mẫu thuộc các dòng còn lại, chúng tôi nhận thấy có các band xuất hiện hay thiếu vắng duy nhất ở cả 3 mẫu thuộc một dòng và có các band xuất hiện hay thiếu vắng duy nhất ở cả 6 mẫu thuộc hai dòng. Từ đó chúng tôi xác lập các chỉ thị phân tử cho việc nhận dạng dòng như sau:

- Nhận dạng dòng 04: Vắng band 520bp mồi UBC 873; Vắng band 700bp mồi UBC 856T (02 chỉ thị đơn); Vắng band 280bp mồi UBC873 đồng thời có band 400bp mồi 17899B; Vắng band 280bp mồi UBC873 đồng thời có band 400bp mồi UBC 856C; Vắng band 280bp mồi UBC873 đồng thời có band 540bp mồi 808; Vắng band 280bp mồi UBC873 đồng thời vắng band 750bp mồi 17899B và Vắng band 280bp mồi UBC873 đồng thời vắng band 1500bp mồi HB13 (07 chỉ thị kép).

- Nhận dạng dòng 05: Vắng band 580bp mồi HB9 đồng thời có band 400bp mồi 17899B; Vắng band 580bp mồi HB9 đồng thời có band 400bp mồi UBC 856C; Vắng band 580bp mồi HB9 đồng thời có band 540bp mồi 808; Vắng band 580bp mồi HB9 đồng thời vắng band 750bp mồi 17899B và Vắng band 580bp mồi HB9 đồng thời vắng band 1500bp mồi HB13 (chỉ có 05 chỉ thị kép).

- Nhận dạng dòng Hải Triều 2: Vắng band 400bp mồi 17899B; Vắng band 400bp mồi UBC 856C; Vắng band 540bp mồi 808; Có band 750bp mồi 17899B và Có band 1500bp mồi HB13 (05 chỉ thị đơn); Có band 890bp 
mồi HB9 nhưng vắng band 700bp mồi 17899B; Vắng band 280bp mồi UBC 873 nhưng có band 520bp mồi UBC 873 và Vắng band 280bp mồi UBC 873 nhưng có band 700bp mồi UBC 856T (03 chỉ thị kép).

- Nhận dạng dòng Hải Triều 1: Có band 790bp mồi HB14 đồng thời có band 400bp mồi 17899B; Có band 790bp mồi HB14 đồng thời có band 400bp mồi UBC 856C; Có band 790bp mồi HB14 đồng thời có band 540bp mồi 808; Có band 790bp mồi HB14 đồng thời vắng band 750bp mồi 17899B; Có band 790bp mồi HB14 đồng thời vắng band 1500bp mồi HB13 và Có band 500bp mồi 844B đồng thời vắng band 700bp mồi 17899B (chỉ có 06 chỉ thị kép).

- Nhận dạng dòng 34: Có band 700bp mồi 17899B (01 thị đơn); Có band 890bp mồi HB9 đồng thời có band 400bp mồi 17899B; Có band 890bp mồi HB9 đồng thời có band 400bp mồi UBC 856C; Có band 890bp mồi HB9 đồng thời có band 540bp mồi 808; Có band 890bp mồi HB9 đồng thời vắng band 750bp mồi 17899B; Có band 890bp mồi HB9 đồng thời vắng band $1500 \mathrm{bp}$ mồi HB13 và Có band 500bp mồi 844B đồng thời có band $890 \mathrm{bp}$ mồi HB9 nhưng có band 400bp mồi 17899B/ band 400bp mồi UBC 856C/ band 540bp mồi 808 hoặc vắng band 750bp mồi 17899B/ band 1500bp mồi HB13 (06 chỉ thị kép).

- Nhận dạng dòng 36: Có band 220bp mồi HB9 (chỉ có 01 chỉ thị đơn)

Thông qua các kết quả thu nhận được, có thể nhận thấy dòng bơ Hải Triều 2 có nhiều chỉ thị đơn để nhận dạng nhất, điều đó cho thấy việc nhận dạng dòng này là dễ dàng hơn cả. Các chỉ thị nhận dạng đơn của dòng này có thể được sử dụng để phát triển các marker nhận dạng kép cho đa số các dòng còn lại. Dòng 05 và Hải Triều 1 chỉ có thể nhận dạng bằng chỉ thị kép. Dòng 34 chỉ có một chỉ thị đơn duy nhất để nhận dạng.

Nhận xét: Có 34 chỉ thị ISSR được xác lập để nhận dạng 06 dòng bơ 04, 05, Hải Triều 2, Hải Triều 1, 34 và 36 bao gồm 9 chỉ thị đơn và 25 chỉ thị kép. 


\section{3. Đánh giá đa dạng di truyền 11 dòng bơ khảo sát}

Với 10 mồi ISSR, chúng tôi thu nhận được đặc trưng nhận dạng của 11 mẫu đại diện cho 11 dòng bơ được khảo sát với 98 band, số band thu nhận được theo từng mồi xin xem ở Bảng 1 . Sử dụng công cụ Excel với các công thức như trình bày trong phương pháp nghiên cứu, chúng tôi thu được kết quả sau như trong Hình 2.
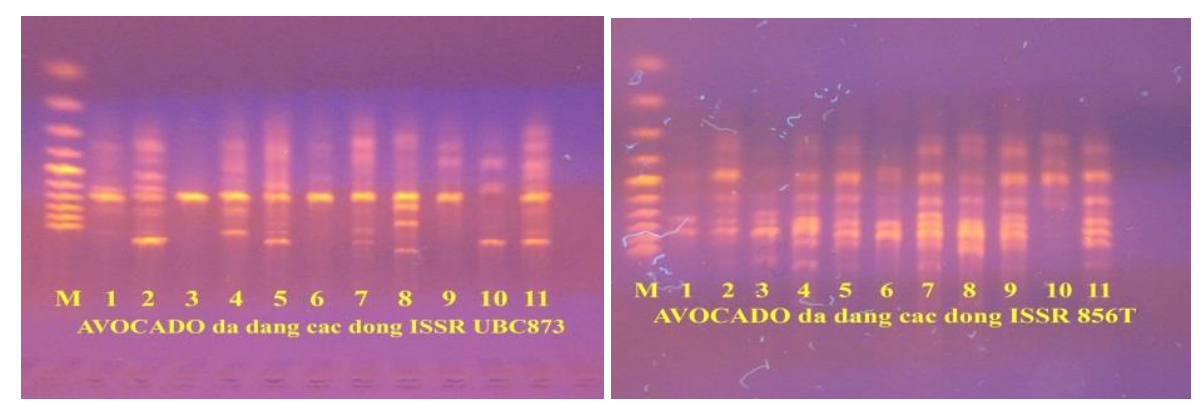

Hình 2. Ảnh gel đặc trưng nhận dạng DNA sử dụng 2 mồi UBC 873 và UBC 856C với tập hộp 11 mẫu khảo sát để đánh giá đa dạng di truyền các dòng bo

Ghi chú: 1: dòng 04, 2: dòng 05, 3: dòng Hải Triều 2, 4: dòng Hải Triều 1, 5: dòng 34; 6: dòng 36; 7 : dòng 34 lai; 8: dòng HO, 9: dòng TO; 10: dòng BM00, 11: dòng BM02.

Các thông số về mức độ đa dạng di truyền của tập hợp 11 dòng bơ khảo sát: Tỷ lệ phần trăm band đa hình: $P P B=91,84 \%$; Mức độ dị hợp trông đợi trung bình (Chỉ số đa dạng gene): $h=H_{\mathrm{e}}=0,3072$ (theo cả hai phương pháp) và Chỉ số Shannon: $I=$ 0,4608. So với các nghiên cứu của Alcaraz và Hormaza (2007) cũng như Eduardo và ctg. (2013), mức độ đa dạng của tập hợp mẫu đại diện cho các dòng khảo sát trong nghiên cứu này là thấp, điều đó chỉ ra rằng các dòng được tạo giống nội địa tại Lâm Đồng có thể có nguồn gốc gần nhau hay được phát triển dần từ một hay một số dòng ban đầu vốn gần nhau. Sự tương đồng di truyền giữa các mẫu khảo sát được thể hiện trong Bảng 3.

Qua kết quả Bảng 3 cho thấy khi so sánh đặc trưng nhận dạng DNA nảy sinh từ 10 mồi ISSR, mức độ tương đồng di truyền giữa các mẫu nằm trong dải từ 0,480 (giữa dòng Hải Triều 1 và dòng BM00) đến 0,806 (giữa dòng Hải Triều 1 và dòng 36), trung bình là 0,649 . Điều này được thể hiện rõ hơn trong cây quan hệ phát sinh giữa các mẫu như trong Hình 3. 


\section{Bảng 3. Tương đồng di truyền giữa các mẫu đại diện cho 11 dòng bơ được khảo sát}

\begin{tabular}{lcccccccccc}
\hline & $\begin{array}{c}\text { Dòng } \\
04\end{array}$ & $\begin{array}{c}\text { Dòng } \\
05\end{array}$ & $\begin{array}{c}\text { Dòng } \\
\text { Hải } \\
\text { Triều 1 }\end{array}$ & $\begin{array}{c}\text { Dòng } \\
\text { Hải } \\
\text { Triều 2 }\end{array}$ & $\begin{array}{c}\text { Dòng } \\
34\end{array}$ & $\begin{array}{c}\text { Dòng } \\
36\end{array}$ & $\begin{array}{c}\text { Dòng } \\
34 \text { lai }\end{array}$ & $\begin{array}{c}\text { Dòng } \\
\text { HO }\end{array}$ & $\begin{array}{c}\text { Dòng } \\
\text { TO }\end{array}$ & $\begin{array}{c}\text { Dòng } \\
\text { BM00 }\end{array}$ \\
\hline Dòng 05 & 0.704 & & & & & & & & & \\
Dòng Hải Triều 1 & 0.704 & 0.633 & & & & & & & & \\
Dòng Hải Triều 2 & 0.694 & 0.622 & 0.704 & & & & & & & \\
Dòng 34 & 0.684 & 0.673 & 0.633 & 0.786 & & & & & & \\
Dòng 36 & 0.755 & 0.663 & 0.806 & 0.673 & 0.684 & & & & & \\
Dòng 34 lai & 0.684 & 0.673 & 0.612 & 0.765 & 0.714 & 0.663 & & & & \\
Dòng HO & 0.612 & 0.602 & 0.561 & 0.673 & 0.684 & 0.592 & 0.704 & & & \\
Dòng TO & 0.612 & 0.622 & 0.520 & 0.653 & 0.643 & 0.612 & 0.786 & 0.776 & & \\
Dòng BM00 & 0.663 & 0.633 & 0.531 & 0.480 & 0.592 & 0.643 & 0.612 & 0.541 & 0.622 & \\
Dòng BM02 & 0.582 & 0.633 & 0.551 & 0.663 & 0.714 & 0.602 & 0.694 & 0.582 & 0.643 & 0.531 \\
\hline
\end{tabular}

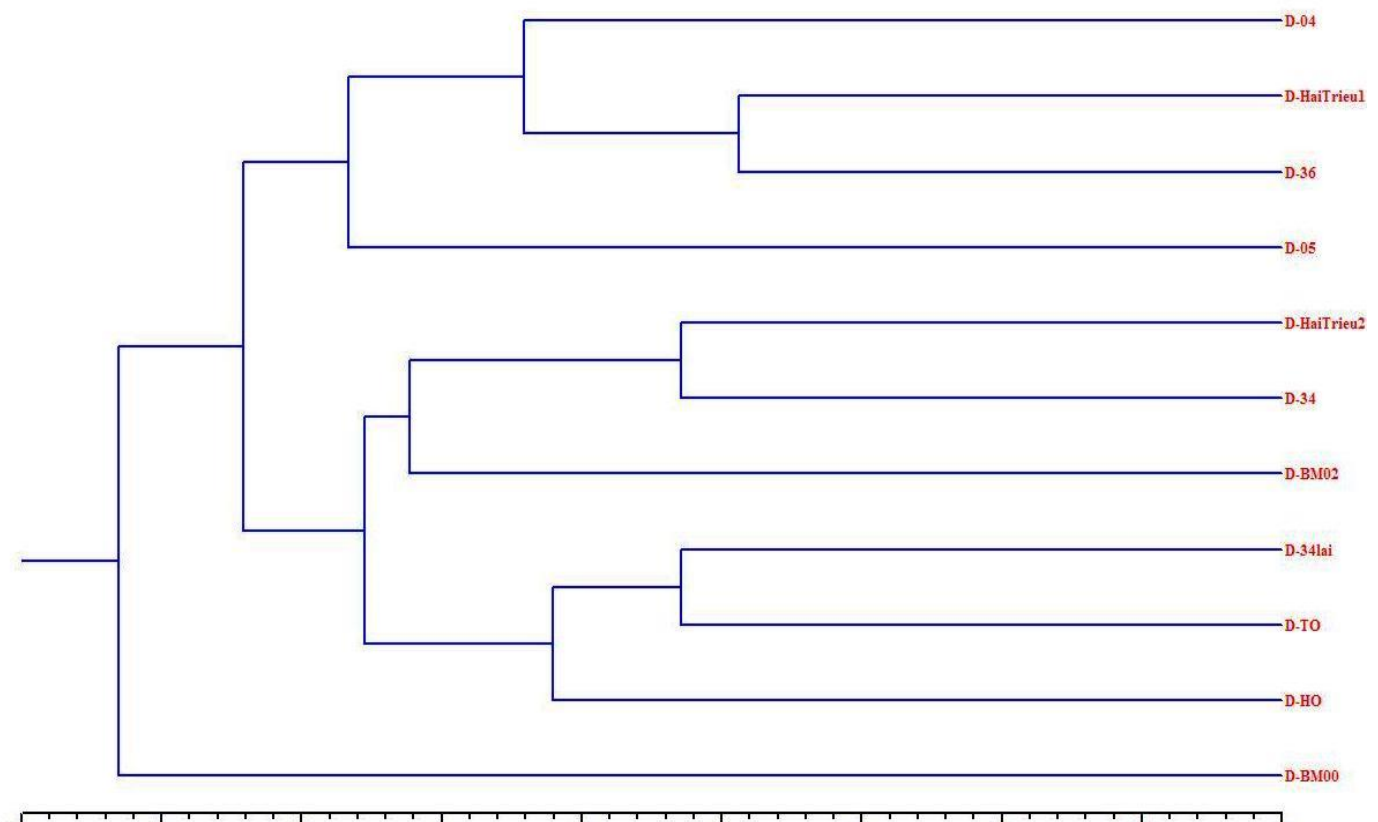

\section{Hình 3. So đồ dạng cây về quan hệ phát sinh giữa các dòng bơ được khảo sát}

Ghi chú: Ký hiệu "D-" các mẫu trong sơ đồ thay cho chữ "Dòng”.

\section{KẾT LUẬN VÀ KIẾN NGH!}

\subsection{Kết luận}

Đã khảo sát tình hình canh tác các dòng bơ bản địa tại Lâm Đồng, ghi nhận đặc điểm 11 dòng quan trọng chủ yếu dựa trên đặc điểm quả và năng suất. Tuy nhiên dữ liệu thu nhận được chỉ là sơ bộ. 
Đã xác lập được 9 chỉ thị đơn và 25 chỉ thị kép để nhận dạng 06 dòng bơ khảo sát. Cả 6 dòng đều xác lập được chỉ thị ISSR để nhận dạng. Kết quả này có thể ứng dụng được cho việc nhận dạng các dòng bơ ngay tại vườn ươm.

Mức độ đa dạng di truyền của 11 dòng bơ được khảo sát thấp: mức dị hợp trông đợi đạt 0,3072, chỉ số Shannon đạt: 0,4608, tỷ lệ band đa hình: 91,84\%. Điều đó cho thấy các dòng bơ được tạo giống và qua tuyển chọn tại Lâm Đồng có nguồn gốc gần nhau.

\subsection{Kiến nghị}

Cần tiến hành nghiên cứu thêm với nhiều mồi ISSR và các kỹ thuật DNA fingerprinting khác để có bộ dữ liệu tốt, dễ ứng dụng hơn trong thực tiễn công tác kiểm tra giống, đặc biệt là giống vườn ươm.

\section{TÀI LIỆU THAM KHẢO}

Ahmad, M. M. A. (2005). Presentation on PCR techniques. Zagazig, Egypt: Department of Genetics, Zagazig University.

Alcaraz, M. L., \& Hormaza, J. I. (2007). Molecular characterization and genetic diversity in an avocado collection of cultivars and local Spanish genotypes using SSRs. Hereditas, 144(6), 244-253.

de Vicente, M. C., Lope, Z. C., \& Fulton, T. (2003). Genetic diversity analysis with molecular marker data: Learning module. International Plant Genetic Resources Institute (IPGRI) and Cornell University.

Eduardo, G., \& Maria, A. V. (2013). Molecular characterization of avocado germplasm with a new set of SSR and EST-SSR markers: Genetic diversity, population structure, and identification of race-specific markers in a group of cultivated genotypes. Tree Genetics \& Genomes, 9(2), 539-555.

Francis, C. Y., Rong-cai, Y., \& Boyle, T. (1999). POPGENE VERSION 1.31 Microsoft Window-based freeware for population genetic analysis - Quick user guide. Cannada: University of Alberta And Centre for International Forestry Research.

Gary, S. B., \& Arpaia, M. L. (2012). Avocado production in California: A cultural handbook for growers. California, USA: The University of California Cooperative Extension, and The California Avocado Society Supported by the California Avocado Commission. 
Gazit, S., \& Degani, C. (2002). Reproductive biology of the avocado. In: Whiley, A.W. Schaffer, B. Wolstenholme, B.N. (eds.): The avocado: Botany, production and uses. Wallingford, UK: CABI Publishing.

John A. M., Greg W. D., Brandon McKee., \& Gary S. (2012). Three new avocado rootstock cultivars tolerant to phytophthora root rot: 'Zentmyer', 'Uzi', and 'Steddom'. HortScience, 47 (8), 1191-1194.

Klein, R. M., \& Klein, D. T. (1979). Phương pháp nghiên cứu thực vật (Nguyễn Tiến Bân và Nguyễn Như Khanh dịch). Hà Nội, Việt Nam: NXB Khoa học Kỹ thuật.

Li, S., Li, J., Yang, X.L., Cheng, Z., \& Zhang, W.J. (2011). Genetic diversity and differentiation of cultivated ginseng (Panax ginseng C. A. Meyer) populations in North-east China revealed by inter-simple sequence repeat (ISSR) markers. Genetic Resource Crope Evolution, 58, 815-824.

Nei, M. (1978). Estimation of average teterozygosity and genetic distance from a small number of individuals. Genetics, 89, 583-590.

Pliego-Alfaro, F., \& Murashige, T. (1988). Somatic embryogenesis in avocado (Persea americana Mill.). Plant Cell Tiss. Org. Cult., 12, 61-66.

Reunova, G. D., Katsa, I. L., Muzaroka, T. I., Nguyen, C. T. P., Dang, T. T., Brennerc, E. V., \& Zhuravleva Y. N. (2011). Diversity of microsatellite Loci in the Panax vietnamensis $\mathrm{Ha}$ et Grushv. (Araliaceae) population. Doklady Biological Sciences, 441, 408-411.

Rohlf, F. J. (2004). NTSYSpc - Numerical taxonomy and multivariate analysis system version 2.1 - User guide. Applied Biostatistics Inc.

Weising, K., Nybom, H., Wolff, K., \& Kahl, G. (2005). DNA fingerprinting in plants principles, methods, and applications ( $2^{\text {nd }}$ edition). UK: CPC Press Taylor \& Fancies group.

Williams, J. G. K., Kubelik, A. R., Livak, K. J., Rafalski, J. A., \& Tingey, S. V. (1990). DNA polymorphisms amplified by arbitrary primers are useful as genetic markers. Nucleic Acids Research, 18, 6531-6535.

Zietkiewicz, E., Rafalski, A., \& Labuda D. (1994). Genome fingerprinting by simple sequence repeat (SSR)-anchored polymerase chain reaction amplification. Genomics, 20, 176-183. 


\title{
GENETIC DIVERSITY INVESTIGATION AND MOLECULAR MARKERS ESTABLISHMENT FOR IDENTIFICATION OF SEVERAL INITIALLY SELECTIVE AVOCADO (Persea americana Miller) STRAINS IN LAMDONG PROVINCE
}

\author{
Le Ngoc Trieu ${ }^{\mathrm{a}^{*}}$, Nguyen Hoang Phong ${ }^{\mathrm{a}}$, Mai Tien Đat ${ }^{\mathrm{a}}$, \\ Thai Thach Bich ${ }^{\mathrm{a}}$, Nguyen Thanh Tien ${ }^{\mathrm{a}}$, Le Đinh Vinh Bao ${ }^{\mathrm{a}}$, \\ Nguyen Khac Quang ${ }^{\mathrm{a}}$, Phan Ngoc Quynh Nhu ${ }^{\mathrm{a}}$ \\ ${ }^{a}$ The Faculty of Biology, Dalat University, Lamdong, Vietnam \\ *Corresponding author: Email: trieuln@dlu.edu.vn \\ Article history \\ Received: July $12^{\text {th }}, 2016$ | Received in revised form: August $30^{\text {th }}, 2016$ \\ Accepted: September 10 $0^{\text {th }}, 2016$
}

\begin{abstract}
Morphologically and genetically investigation and estimation are necessary for train/cultivar identification and breeding in many crops. Materials from several selective avocado strains in Lamdong province were collected for genetic diversity analysis and strain identification. Initially morphological characteristics of fruit and yield data of 11 avocado strains were recorded to contribute to data establishment for strain identification data. DNA fingerprints recorded with 10 ISSR primers including 125 electrophoresis DNA band were used for genetic diversity estimation of 11 investigated strains set, in the result, the average expected heterozygosity (gene diversity) was $H_{e}=h=0.3072$, Shannon index was $I=0.4608$, and percentage of polymorphic bands was $P P B=91.84 \%$. Also with the same 10 ISSR primers, DNA fingerprints recorded from 18 samples (3 samples per strain) including 98 electrophoresis DNA band were used for identification 06 investigated avocado strains. Based on the occurrence or absence of specific electrophoresis DNA band, 9 single ISSR markers and 25 double/multiple ISSR markers were established to identify these 6 strains. These initially achieved results provide the necessary data for avocado breeding and development in general and identification 6 potential avocado strains.
\end{abstract}

Keywords: Expected heterozygosity; ISSR; Molecular marker; Shannon index. 